\title{
Imaging features of intraductal papillary mucinous neoplasms of the pancreas in multi-detector row computed tomography
}

\author{
Ling Tan, Ya-E Zhao, Deng-Bin Wang, Qing-Bing Wang, Jing Hu, Ke-Min Chen, Xia-Xing Deng
}

Ling Tan, Deng-Bin Wang, Qing-Bing Wang, Jing Hu, KeMin Chen, Department of Radiology, Ruijin Hospital, Shanghai Jiao Tong University, School of Medicine, Shanghai 200025, China

Ya-E Zhao, Department of Radiology, Shanghai Shi Dong Hospital, Shanghai 200438, China

Xia-Xing Deng, Department of General Surgery, Ruijin Hospital, Shanghai Jiao Tong University, School of Medicine, Shanghai 200025, China

Author contributions: Tan L and Zhao YE contributed equally to this work; Wang DB and Chen KM designed the research; Tan L, Zhao YE, Wang DB, Wang QB, Hu J, Chen KM and Deng XX performed the research; Tan L, Zhao YE and Wang DB analyzed the data and wrote the paper; All the authors reviewed and approved the final manuscript.

Supported by Shanghai Leading Academic Discipline Project, No. S30203

Correspondence to: Deng-Bin Wang, MD, PhD, Professor of Radiology, Vice Chair, Department of Radiology, Ruijin Hospital, Shanghai Jiao Tong University, School of Medicine, 197 Ruijin Er Road, Shanghai 200025,

China.dbwang8@yahoo.com.cn

Telephone: +86-21-64370045-665724 Fax: +86-21-64333548

Received: May 6, 2009

Revised: August 1, 2009

Accepted: August 8, 2009

Published online: August 28, 2009

\section{Abstract}

AIM: To retrospectively evaluate the imaging features of pancreatic intraductal papillary mucinous neoplasms (IPMNs) in multi-detector row computed tomography (MDCT).

METHODS: A total of 20 patients with pathologicallyconfirmed intraductal papillary mucinous neoplasms (IPMNs) were included in this study. Axial MDCT images combined with CT angiography (CTA) and multiplanar volume reformations (MPVR) or curved reformations (CR) were preoperatively acquired. Two radiologists (Tan $L$ and Wang DB) reviewed all the images in consensus using an interactive picture archiving and communication system. The disputes in readings were resolved through consultation with a third experienced radiologist (Chen $\mathrm{KM})$. Finally, the findings and diagnoses were compared with the pathologic results.

RESULTS: The pathological study revealed 12 malignant IPMNs and eight benign IPMNs. The diameters of the cystic lesions and main pancreatic ducts (MPDs) were significantly larger in malignant IPMNs compared with those of the benign IPMNs $(P<0.05)$. The combinedtype IPMNs had a higher rate of malignancy than the other two types of IPMNs $(P<0.05)$. Tumors with mural nodules and thick septa had a significantly higher incidence of malignancy than tumors without these features $(P<0.05)$. Communication of side-branch IPMNs with the MPD was present in nine cases at pathologic examination. Seven of them were identified from CTA and MPVR or CR images. From comparison with the pathological diagnosis, the sensitivity, specificity, and accuracy of MDCT in characterizing the malignancy of IPMN of the pancreas were determined to be $100 \%$, $87.5 \%$ and $95 \%$, respectively.

CONCLUSION: MDCT with CTA and MPVR or CR techniques can elucidate the imaging features of IPMNs and help predict the malignancy of these tumors.

\section{(C) 2009 The WJG Press and Baishideng. All rights reserved.}

Key words: Computed tomography; Diagnostic imaging; Intraductal papillary mucinous neoplasm; Pancreatic neoplasms

Peer reviewer: Dr. Serdar Karakose, Professor, Department of Radiology, Meram Medical Faculty, Selcuk University, Konya 42080, Turkey

Tan L, Zhao YE, Wang DB, Wang QB, Hu J, Chen KM, Deng $\mathrm{XX}$. Imaging features of intraductal papillary mucinous neoplasms of the pancreas in multi-detector row computed tomography. World J Gastroenterol 2009; 15(32): 4037-4043 Available from: URL: http://www.wjgnet.com/1007-9327/15/4037.asp DOI: http://dx.doi.org/10.3748/wjg.15.4037

\section{INTRODUCTION}

Intraductal papillary mucinous neoplasms (IPMNs) of the pancreas, defined by the World Health Organization (WHO), are a broad spectrum of neoplasms arising from the pancreatic duct epithelia and characterized by cystic dilatation of the main and/or branch pancreatic ducts, and occasionally by the presence of mural nodules (papillary excrescence or protuberances) ${ }^{[1-6]}$. According to 
the site and extent of involvement, IPMNs are classified into three subtypes: main duct type, branch duct type, and combined-type (mixed type) with both main and branch duct lesions ${ }^{[2,7,8]}$. Although an IPMN is a rare tumor, the increasingly common use of imaging techniques has contributed to the identification of an increasing number of the lesions, even in entirely asymptomatic cases ${ }^{[9-13]}$.

According to the International Guidelines for management of IPMN ${ }^{[2]}$, magnetic resonance imaging (MRI) along with magnetic resonance cholangiopancreatography (MRCP) is referred to as the best imaging modality to outline the gross appearance of IPMN. However, computed tomography (CT) is still the mainstay in the evaluation of patients with IPMNs of the pancreas. Improvements in CT such as the evolution of post-processing techniques in multi-detector row CT (MDCT), have enhanced the capability of CT in the evaluation of abnormalities of the pancreatic parenchyma and the pancreatic ducts in patients with IPMNs ${ }^{[10]}$. Axial CT images combined with multiplanar volume reformations (MPVR) or curved reformations (CR) and CT angiography (CTA) with maximum intensity projection should display the imaging features of IPMNs in more detail. Recent studies assessed the capability of MDCT in defining the invasiveness of the IPMN and in evaluating the resectability of $\mathrm{IPMNs}^{[14,15]}$. The IPMN can evolve through all biological stages, from slight dysplasia to carcinoma. As one of the few surgically curable pancreatic tumors, accurate preoperative prediction of malignancy remains one of the major issues in the optimal treatment of IPMNs, and it also influences the outcome of the resection $^{[16,17]}$.

The present study retrospectively assessed the imaging findings of IPMNs with MDCT and evaluated the capabilities of MDCT with emphasis on the postprocessing techniques to predict the malignancy of IPMNs.

\section{MATERIALS AND METHODS}

\section{Patient population}

Between December 2005 and March 2008, IPMN of the pancreas was diagnosed in 31 cases at our institution based on surgico-pathological examination. Of these 31 cases, 20 patients [11 male, 9 female; mean age, 62 years (range, 41-81 years)] who underwent MDCT within a month prior to surgery were recruited into this study. At our hospital, surgical planning requires that most patients in whom IPMN of the pancreas is suspected undergo MDCT including CTA and MPVR or CR processing rather than dynamic MRI with MRCP for evaluation of the extent of the disease and the relationship between affected parts of the pancreas and surrounding vessels and organs. The lesions revealed by the subsequent pathological examinations were divided into three subtypes: benign adenoma, noninvasive carcinoma including borderline malignancy and carcinoma in situ, and invasive carcinoma in accordance with the WHO classification. A borderline lesion was defined as a tumor which was not overtly malignant but had some foci of severe cellular atypia, indicating that it should be treated as malignant. Thus, an IPMN considered at imaging to be malignant could include a borderline malignancy, carcinoma in situ, and invasive carcinoma on pathology in this study. The mean interval between the imaging and surgery was $22 \mathrm{~d}$ (range, 10-31 d). Institutional Review Board approval and waiver of informed consent for this retrospective study were obtained.

\section{CT techniques}

All CT examinations were performed with a 4- or 16-slice MDCT scanner (Lightspeed QX/I or Lightspeed 16; GE Medical Systems, Milwaukee, Wis). The parameters applied in the CT scan were as follows: a tube voltage of $120 \mathrm{kVp}$, a tube current of $280 \mathrm{~mA}$, and tube rotation time of $0.5-0.8 \mathrm{~s}$. Prior to administration of contrast agents, non-enhanced CT of the upper abdomen was performed with $10 \mathrm{~mm}$ slice thickness and $10 \mathrm{~mm}$ spacing. Non-ionic contrast materials with an iodine concentration of $300 \mathrm{mgI} / \mathrm{mL}$ were injected into the antecubital vein at a rate of $3-4 \mathrm{~mL} / \mathrm{s}$ with an 18 -20-gauge cannula for all the patients. In addition, $40 \mathrm{~mL}$ dextrose was administered at the same rate immediately after the administration of contrast agents. The pancreatic phase of dual phased CT was started at $35 \mathrm{~s}$ after the initiation of contrast material injection, whereas the venous phase was performed afterwards with a delayed time of 65-70 s. For the pancreatic phase, a slice thickness of $1.25 \mathrm{~mm}$ and a table speed of $11.25 \mathrm{~mm} / \mathrm{s}$ were utilized while a slice thickness of $5 \mathrm{~mm}$ and a table speed of $18.75 \mathrm{~mm} / \mathrm{s}$ were employed for the venous phase. Axial images were retrospectively reconstructed at a $50 \%$ overlap, using a 1.25 $\mathrm{mm}$ slice thickness, and $0.625 \mathrm{~mm}$ spacing.

In all patients, CTA and 2-dimensional (2D) MPVR or CR images were generated from the source axial images at a commercially available dedicated workstation (ADW 4; GE Medical Systems) by a radiologist (Zhao YE).

\section{Image analysis}

Two radiologists (Tan $\mathrm{L}$ and Wang DB) reviewed all the images in consensus at an interactive picture archiving and communication system workstation. The readers were aware of the diagnosis of an IPMN but were blinded to the findings of surgery and pathological examination. In cases of interobserver disagreement, final decisions were made through consultation with a third experienced radiologist (Chen KM).

Each reader recorded the following items: (1) the largest diameter of the cystic lesion; (2) the largest diameter of the main pancreatic duct (MPD); (3) classification of the tumors as main duct type, branch duct type, and combined type (mixed type). The main duct type was diagnosed when dilatation of the MPD had increased its diameter to more than $5 \mathrm{~mm}$. The presence of one or multiple cystic lesions in the pancreatic parenchyma, without dilatation of the MPD, indicated that a branch duct-type tumor was present. The combined type was diagnosed when the pancreas contained one or more cystic lesions and the diameter of the dilated MPD was more than $5 \mathrm{~mm}$; (4) locations of the lesions: in the head or uncinate process, the body, or the tail of the pancreas. Diffuse involvement was denoted when the lesion involved the entire gland; (5) internal solid structures: presence or absence of mural nodules and thick septa; (6) other findings including vascular involvement, lymph node enlargement, 


\begin{tabular}{|c|c|c|c|}
\hline \multirow[t]{2}{*}{ MDCT findings } & \multicolumn{2}{|c|}{ Surgical and pathological results } & \multirow[t]{2}{*}{$P$} \\
\hline & Benign $(n=8)$ & Malignant $(n=12)$ & \\
\hline $\begin{array}{l}\text { Largest diameter of } \\
\text { cystic lesion }\end{array}$ & $21.6 \pm 10.3 \mathrm{~mm}$ & $43.5 \pm 16.5 \mathrm{~mm}$ & $<0.05$ \\
\hline $\begin{array}{l}\text { Caliber of main } \\
\text { pancreatic duct }\end{array}$ & $3.3 \pm 1.6 \mathrm{~mm}$ & $7.5 \pm 5.5 \mathrm{~mm}$ & $<0.05$ \\
\hline Morphologic type & & & $<0.05$ \\
\hline Branch duct & 4 & 1 & \\
\hline Combined & 2 & 10 & \\
\hline Main duct & 2 & 1 & \\
\hline Location of cystic lesion & & & $>0.05$ \\
\hline Head and uncinate & 4 & 10 & \\
\hline Body & 0 & 1 & \\
\hline Tail & 2 & 0 & \\
\hline Diffuse & 2 & 1 & \\
\hline $\begin{array}{l}\text { Solid structures inside } \\
\text { lesion }\end{array}$ & & & $<0.05$ \\
\hline $\begin{array}{l}\text { Mural nodules and } \\
\text { thick septa }\end{array}$ & 2 & 10 & \\
\hline $\begin{array}{l}\text { No mural nodules } \\
\text { or thick septa }\end{array}$ & 4 & 1 & \\
\hline
\end{tabular}

MDCT: Multi-detector row computed tomography; IPMNs: Intraductal papillary mucinous neoplasms.

and duodenal involvement, as well as dilatation of the bile duct and distant metastasis. All the imaging diagnoses were compared with the surgico-pathological outcomes.

\section{Statistical analysis}

The unpaired Student's $t$-test was used to assess the differences in the largest diameters of the cystic lesion and MPDs between the benign and malignant groups. Fisher's exact test was used to evaluate the differences in classification, location, and internal solid structures between the benign and malignant tumors confirmed by pathology. The sensitivity, specificity, and accuracy of the MDCT diagnosis for IPMNs of the pancreas were calculated. $P<0.05$ was considered statistically significant. Statistical analysis was performed with SPSS 13.0 computer software (Chicago, IL, USA).

\section{RESULTS}

\section{Pathologic results}

Five patients (5 of 20,25\%) had invasive carcinoma, whereas seven patients ( 7 of $20,35 \%$ ) had a noninvasive carcinoma (including three borderline lesions and four carcinoma in situ). Both of these lesions were regarded as malignant in this study. The lesions in the other eight patients ( 8 of $20,40 \%$ ) were classified as benign IPMNs by pathology. Among the 12 malignant IPMNs, two patients had duodenal involvement with one also having vascular involvement, another two patients had regional lymph node metastasis on surgico-pathological examination, and one patient only had vascular involvement.

\section{Imaging features of IPMNs compared with surgico- pathological results}

The imaging features of IPMNs at MDCT are summa-

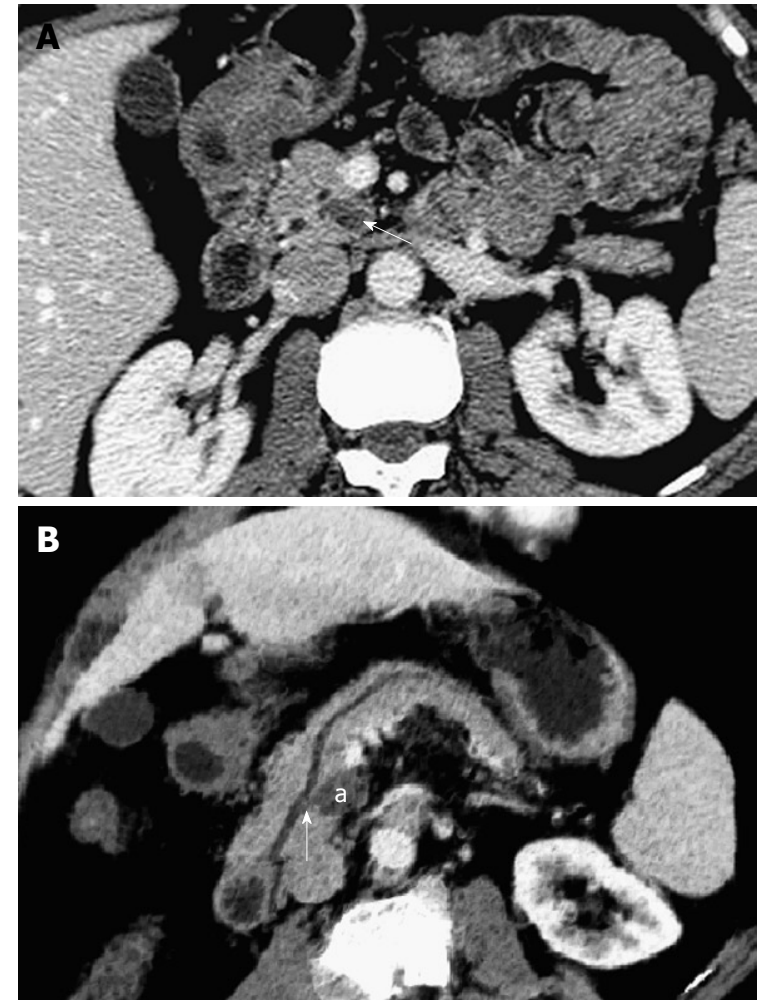

Figure 1 Pathologically confirmed benign branch-duct-type IPMN in a 47-year-old woman with abdominal discomfort for about $6 \mathrm{mo}$. A: There was a 2-cm cystic mass (white arrow) in the uncinate process of the pancreas at the axial abdominal MDCT image; $B$ : The cystic mass (a) in the posterior pancreatic parenchyma was demonstrated with a communication (white arrow) between the mass and the main pancreatic duct which was slightly dilated in the curved reformed $(\mathrm{CR})$ image.

rized in Table 1. The largest diameters of the cystic lesions were $21.6 \pm 10.3 \mathrm{~mm}$ and $43.5 \pm 16.5 \mathrm{~mm}$ for benign and malignant IPMNs, respectively. A statistically significant difference has been demonstrated between the sizes of the lesions of benign and malignant IPMNs $(P<0.05)$. The mean diameter of most dilated segments of MPD was $3.3 \pm 1.6 \mathrm{~mm}$ in patients with benign IPMNs, and 7.5 $\pm 5.5 \mathrm{~mm}$ in patients with malignant IPMNs. The diameter of the MPD was significantly larger in patients with malignant IPMNs compared with that of benign cases $(P<0.05)$ (Figure 1). Based on MDCT findings, five patients (5 of $20,25 \%$ ) were classified as branch duct type, three patients ( 3 of $20,15 \%$ ) as main duct type, and $12 \mathrm{pa}-$ tients (12 of $20,60 \%$ ) as combined type. With pathological correlation, malignant IPMNs presented in one of the five patients with branch duct type, one of three patients with main duct type, and 10 of the 12 patients with combined type. Significant correlation was shown between the type of ductal involvement and the pathological results. The combined type also had a higher rate of malignancy $(P<0.05)$ (Figure 2). Three combined-type cases had accompanying marked dilatation of the biliary tracts including extrahepatic and intrahepatic bile ducts (Figure 3). The pancreatic head and uncinate process were the most common locations of IPMNs, accounting for 70\% (14 of 20). Malignant IPMNs presented in 10 of these 14 patients with an incidence of $83.3 \%$ (10 of 12) among all the malignant cases. Only one malignant IPMN identified 

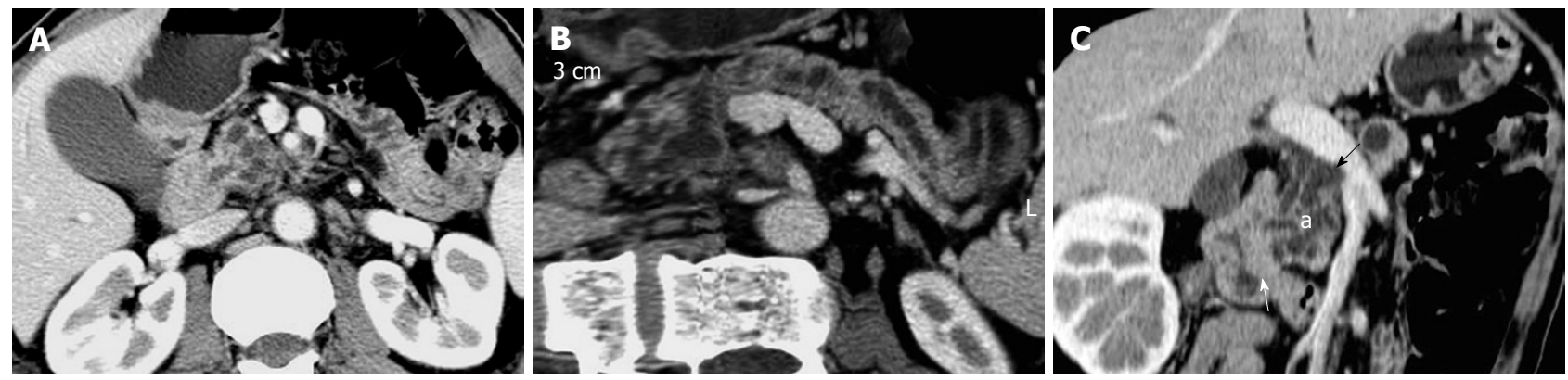

Figure 2 Pathologically confirmed malignant combined-type IPMN in a 41-year-old man with abdominal and back pain for about 2 years. A: A $4 \mathrm{~cm}$ cystic mass with multiple septa arising from the pancreatic head was revealed in the axial MDCT image; B: Besides the cystic mass in the pancreatic head, the profile of the main pancreatic duct, which was severely dilated, was depicted on the CR image; $C$ : The cystic lesion (a) in the pancreatic head invaded the duodenum and main portal vein resulting in the duodenal wall thickening (white arrow) with marked enhancement and irregular narrowing (dark arrow) of the vessel in the multiplanar volume reformation (MPVR) image.
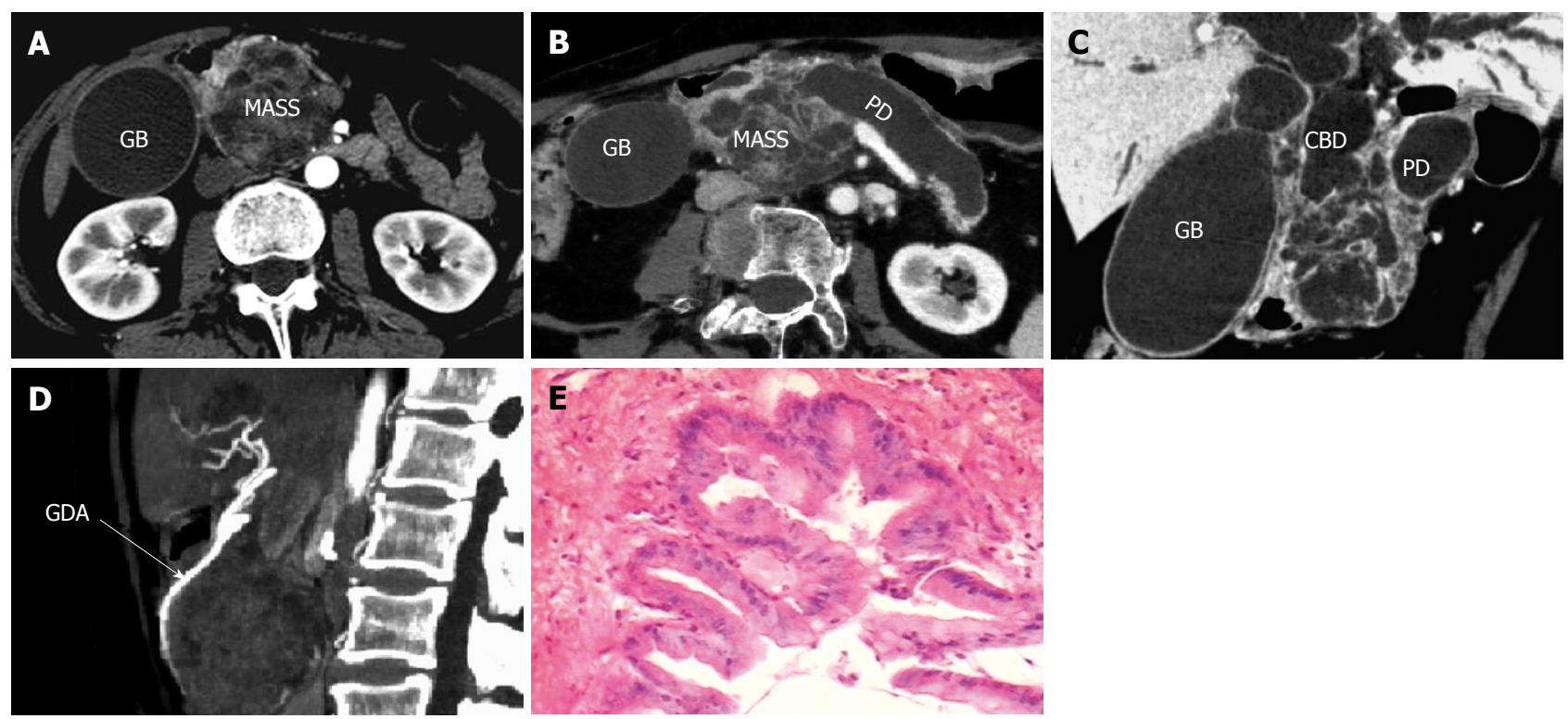

Figure 3 Pathologically confirmed malignant combined-type IPMN in a 65-year-old man with jaundice and abdominal pain for about 1 year. A: An $8 \mathrm{~cm}$ cystic and solid mass (MASS) was seen in the axial arterio-phased MDCT image with contrast agents. The gallbladder (GB) was distended; $B$ : The heterogeneous mass was shown with severe dilatation of the main pancreatic duct (PD) and the gallbladder (GB) in the CR image; $C$ : The profile of the dilatation of pancreatobiliary system (CBD, common bile duct) was entirely depicted in the MPVR image; D: The gastroduodenal artery (GDA) showed irregularity as a result of infiltration of the tumor; $E$ : The tumor consisted of papillary proliferations of tall columnar mucin-producing epithelium. Atypical epithelium characterized by enlarged nuclei (HE, × 150).
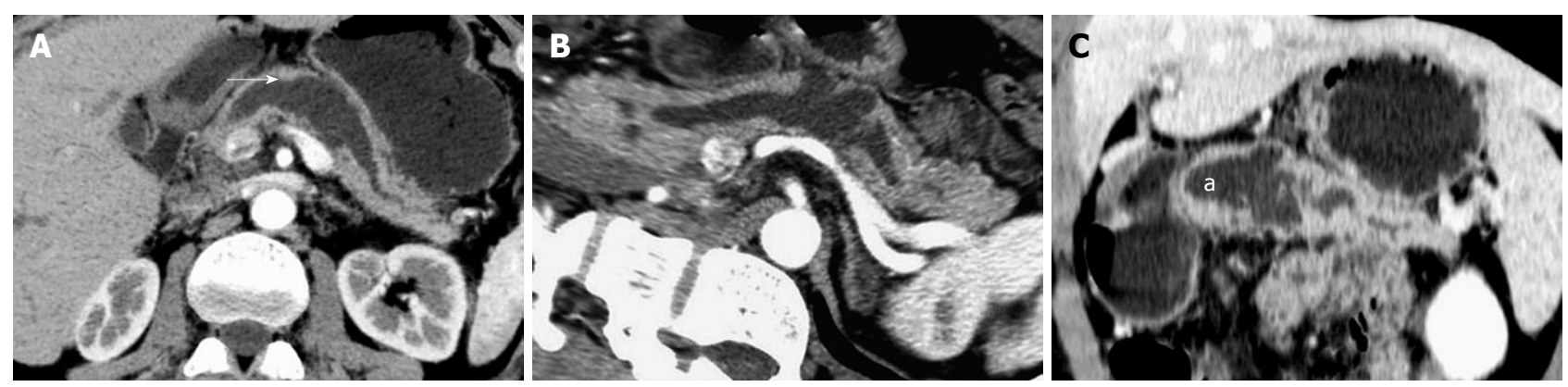

Figure 4 Pathologically confirmed malignant combined-type IPMN in a 55-year-old man with abdominal pain for 1.5 years. A: A $3 \mathrm{~cm} \times 10 \mathrm{~cm}$ longitudinally cystic mass in the pancreatic body was shown with a mural nodule (white arrow) in the axial MDCT images; $B$ : The classification of combined type for this case was accurately defined by the $\mathrm{CR}$ image; $\mathrm{C}$ : The profile of the cystic mass (a) and dilatation of the branch duct and the upstream pancreatic duct were identified in the MPVR images.

by MDCT was located at the body of the pancreas (Figure 4), whereas the IPMNs arising from the pancreatic tail in two cases were both benign and verified by pathology. The other three ( 3 of $20,15 \%$ ) cases had diffuse lesions, and one of these $(33.3 \%)$ was malignant. Among 17 branch duct-type and combined-type lesions, mural nodules and thick septa were seen in 12 cases (Figure 4). Ten of these 12 were referred to as malignant IPMNs on pa- 
thology. Tumors with mural nodules and thick septa had a significantly higher incidence of malignancy than tumors without them $(P<0.05)$.

No distant metastasis was revealed on MDCT in any of the patients. Vascular invasion was revealed in two patients from CTA images (Figure 2), and was proven by surgico-pathological studies. Lymph node enlargement was seen in three patients on axial CT images, but one was a false-positive when compared with the results of pathological examination. Two patients had duodenal involvement depicted by MPVR images and confirmed by pathological examination (Figure 2), and one of these had vascular involvement. Vascular involvement was also detected in another case. Communication of sidebranch IPMNs with the MPD was present in nine cases at pathological examination. Seven of these $(77.7 \%, 7$ of 9) were identified from CTA and MPVR images (Figure 1).

From a comparison with the pathological outcomes, the sensitivity, specificity, and accuracy of MDCT in characterizing the malignancy of IPMN of the pancreas were determined to be $100 \%, 87.5 \%$ and $95 \%$, respectively.

\section{DISCUSSION}

After the first report of IPMN in 1982, this tumor entity has been increasingly recognized over the past decades as a result of the markedly improved imaging modalities ${ }^{[18,19]}$. IPMNs mainly occur in the 6th to 7 th decades of life, affecting males slightly more frequently than females. IPMNs account for $0.5 \%$ of all pancreatic neoplasms found at autopsy, $7.5 \%$ of clinically diagnosed pancreatic neoplasms, and $16.3 \%$ of surgically resected pancreatic neoplasms ${ }^{[20]}$. The IPMN was histologically defined by the WHO as "intraductal mucin-producing neoplasm with tall columnar mucin-containing epithelium with or without papillary projections, involving the MPD and/or major side branches" ${ }^{\text {"21] }}$. The IPMN is also believed by some to follow the so-called "adenoma-carcinoma" sequence ${ }^{[19]}$. Sohn et al ${ }^{[22]}$ reported that there appears to be a lag time of approximately 5 years in the progression from adenoma to invasive carcinoma and that progression to invasive carcinoma occurs relatively quickly once moderate dysplasia is found. Kawai et al ${ }^{[1]]}$ reported that the malignancy rate of IPMNs was $48 \%$ while it was $67 \%$ in the study conducted by Lopez Hänninen et al ${ }^{[23]}$. In our study, the malignancy rate was $60 \%$ (12 of 20). The treatment decision with regard to IPMN is often based on the patient's age at presentation, the lesion location in the pancreas, the extent of ductal involvement, and also the presence or absence of malignant features ${ }^{[24]}$. Since most of the main duct IPMNs will progress into invasive carcinomas, the resection of main duct IPMNs and mixed variant IPMNs is recommended if the patient is a good surgical candidate with a reasonable life expectancy ${ }^{[2,25,26]}$. Currently, the crosssectional imaging studies including MDCT and MRI with MRCP play a crucial role in structuring the treatment protocol for the patients with IPMNs.

Since the MDCT is widely used in clinical practice, more and more IPMNs are detected. Because of the overproduction of mucus, MPD dilatation can occur both proximal and distal to the tumor. In our study, most (14 of 20) of the IPMNs were located at the head and uncinate process of the pancreas, but there was no statistically significant differences in the distribution of the lesion locations because of the bias resulting from the small size of the patient population in this group. However, the cystic lesions in the pancreatic parenchyma and the diameter of the MPD in malignant IPMNs presented with significantly larger sizes than the benign IPMNs $(P<0.05)$. More combined-type IPMNs were malignant than the other two subtypes $(P<0.05)$. The MDCT features most specific for a malignant IPMN were mural nodules and thick septa inside the lesion $(10$ of 20) in this group as indicated in the literature ${ }^{[27,28]}$. Thinner-slice reformed CTA and MPVR or CR images showed other malignant signs clearly, including vascular invasion, lymph node enlargement, and duodenal involvement, as well as dilatation of the common bile duct and common hepatic duct (Figure 3). Ogawa et a ${ }^{[15]}$ reported that the sensitivity, specificity, and accuracy for identifying malignancy were $83 \%, 81 \%$ and $82 \%$ and for identifying pancreatic parenchymal invasion were $90 \%, 88 \%$ and $89 \%$, respectively. According to the International Consensus Guidelines for management of IPMN, the branch duct IPMNs are benign more frequently than the main duct IPMNs ${ }^{[2]}$. The data in this study also complied with this rule. However, compared with the published series from Europe, Japan, and the $\mathrm{USA}^{[9,29-32]}$, the main duct IPMN had a lower rate of malignancy ( 1 of 3 ) in the present study, whereas the combined-type IPMNs demonstrated malignancy in more cases (10 of 12) on pathology. The sensitivity, specificity, and accuracy of MDCT in characterizing the malignancy of IPMNs were $100 \%, 87.5 \%$ and $95 \%$, respectively. They were a little bit higher than the data in the published literature $e^{[2,15]}$. This could be explained possibly by the bias generated by the small number of purely main duct IPMNs and the limited size of the entire patient population in this group. Moreover, because of the limited cases of IPMN recruited in the present study, we considered the noninvasive carcinoma including borderline malignancy and carcinoma in situ, and invasive carcinoma together as a malignancy for analysis. On the other hand, this strategy without separation of the noninvasive and invasive carcinoma should be quite reasonable in the clinical context since progression from noninvasive malignancy to invasive carcinoma occurs relatively quickly once moderate dysplasia is found ${ }^{[22]}$. To some extent, the noninvasive carcinoma including borderline malignancy and carcinoma in situ should attract as much attention as invasive carcinoma in this setting where even the benign adenoma can progress to carcinoma in only 5 years ${ }^{[22]}$. Therefore, more prospective studies with a big IPMN population are required in order to reveal the more accurate profile of Chinese patients in the future.

Compared with the combined type IPMNs, patients with the branch-duct type IPMN without malignant features can be managed by follow-up examinations instead of surgery, particularly when the patient refuses surgery, or when the patient is in poor condition with other severe concomitant disease ${ }^{[33]}$. Thus, the imaging 
modalities such as MDCT could be valuable in deciding whether the patient should undergo surgery or followup in most cases. The presence of communication of the pancreatic cystic lesion with the MPD is one of the most reliable findings for the diagnosis of branch duct IPMN $^{[34]}$. With routine transverse CT scanning of the pancreas, the communicating duct is not easily seen. MPVR or CR images can markedly increase the chance of identification of the interaction.

Normally, IPMNs have a better outcome and prognosis compared to pancreatic ductal adenocarcinomas. The overall 5-year survival rate has been reported to exceed $80 \%$ for noninvasive IPMNs and $50 \%$ for the invasive malignant IPMNs ${ }^{[19]}$. Therefore, correct evaluation of IPMN is extremely important as a recent analysis has suggested that this entity is one of the few surgically curable pancreatic neoplasms ${ }^{[18]}$. Prior investigations showed MRI with MRCP was useful for assessment of IPMN as a noninvasive approach ${ }^{[23,35,36]}$. However, its spatial resolution is not as high as that of CT. Moreover, MDCT scanning is fast enough to acquire all necessary imaging data during a single breath-hold in which much thinner sliced images can be generated. It is less subject to respiratory motion and partial-volume effects than MRI ${ }^{[37,38]}$. Since most of the patients are elderly, the abovementioned characteristics of MDCT seem to be important for patients with IPMNs. With CTA and MPVR or CR images using 3D or 2D modes in different planar directions, MDCT can show the lesion itself, the surrounding structures, and the nearby vessels, as well as the bile duct during one set of CT scans. The reformed images of bile ducts were similar to the MRCP image (Figure 3). Dilatation of the bile ducts and the enlarged gallbladder could be clearly depicted. With the postprocessing techniques, CTA and MPVR or CR images can be generated with more details about the IPMN and the surrounding parenchyma or adjacent vessels.

In conclusion, MDCT scanning with CTA and MPVR or CR techniques can help predict malignant IPMN by differentiating the various types of ductal involvement and demonstrating the mural nodules and thick septa of the lesion, the MPD dilatation of the combined subtypes, the size of the cystic lesion as well as the involvement of surrounding structures. MDCT can be referred to as the diagnostic tool of choice for accurate evaluation of IPMN before treatment.

\section{COMMENTS}

\section{Background}

Intraductal papillary mucinous neoplasm (IPMN) mainly occurs in the 6th to 7th decades of life, affecting males slightly more frequently than females. IPMN accounts for $0.5 \%$ of all pancreatic neoplasms found at autopsy, $7.5 \%$ of clinically diagnosed pancreatic neoplasms, and $16.3 \%$ of surgically resected pancreatic neoplasms. The increasingly common use of imaging techniques has contributed to the identification of an increasing number of the lesions, even in entirely asymptomatic cases.

\section{Research frontiers}

Accurate preoperative evaluation of an IPMN is extremely important for the clinician involved in the diagnosis and further evaluation and intervention, as it is one of the few surgically curable pancreatic neoplasms. However, main duct and combined type IPMNs are more likely to be malignant with biological aggressiveness. A noninvasive imaging approach is the tool of choice for assessing an IPMN of the pancreas preoperatively and can provide accurate information for planning treatment protocols. Although magnetic resonance imaging with magnetic resonance cholangiopancreatography is referred to as the best imaging modality to outline the gross appearance of IPMNs, computed tomography (CT) is still the mainstay in evaluation of patients with IPMNs of the pancreas. Moreover, multi-detector row CT (MDCT) scanning is fast enough to acquire all the necessary imaging data during one single breath-hold in which much thinner sliced images can be generated for reformations.

\section{Innovations and breakthroughs}

There is limited published literature concerning the prediction of malignancy of IPMNs of the pancreas. In this series, the combined-type IPMNs had a higher rate of malignancy than the other two types of IPMNs $(P<0.05)$. The diameters of the cystic lesion and main pancreatic duct (MPD) were significantly larger in malignant tumors compared with those of benign IPMNs $(P<0.05)$. Tumors with mural nodules and thick septa had a significantly higher incidence of malignancy than tumors without these features $(P<0.05)$. In comparing with the pathological results, the sensitivity, specificity, and accuracy of MDCT in characterizing the malignancy of IPMN of the pancreas were determined as $100 \%, 87.5 \%$ and $95 \%$, respectively. The imaging findings were predictive of the malignancy of the IPMNs.

\section{Applications}

Based on their research, MDCT scanning with CT angiography (CTA) and MPVR or CR techniques can help predict malignant IPMN by differentiating the various types of ductal involvement and demonstrating the mural nodules and thick septa of the lesion, the MPD dilatation of the combined subtypes, the size of the cystic lesion as well as the involvement of surrounding structures. MDCT can be referred to as the diagnostic tool of choice in accurate evaluation of IPMN before treatment.

\section{Terminology}

IPMN: histologically defined by the World Health Organization as an "intraductal mucin-producing neoplasm with tall columnar mucin-containing epithelium with or without papillary projections, involving the MPD and/or major side branches"; MDCT: multiple detectors applied to CT. This modality can improve the scanning speed and spatial resolution dramatically. Furthermore, MDCT is intrinsically suitable for CTA scanning.

\section{Peer review}

The authors evaluated the predictive factors for the presence of malignancy associated with IPMN based on their own data. It is well organized and an overall theoretical analysis is given. The conclusions are scientifically reliable and valuable.

\section{REFERENCES}

1 Bernard P, Scoazec JY, Joubert M, Kahn X, Le Borgne J, Berger F, Partensky C. Intraductal papillary-mucinous tumors of the pancreas: predictive criteria of malignancy according to pathological examination of 53 cases. Arch Surg 2002; 137: 1274-1278

2 Tanaka M, Chari S, Adsay V, Fernandez-del Castillo C, Falconi M, Shimizu M, Yamaguchi K, Yamao K, Matsuno S. International consensus guidelines for management of intraductal papillary mucinous neoplasms and mucinous cystic neoplasms of the pancreas. Pancreatology 2006; 6: 17-32

3 Kimura W, Nagai H, Kuroda A, Muto T, Esaki Y. Analysis of small cystic lesions of the pancreas. Int J Pancreatol 1995; 18: 197-206

4 Fernández-del Castillo C, Targarona J, Thayer SP, Rattner DW, Brugge WR, Warshaw AL. Incidental pancreatic cysts: clinicopathologic characteristics and comparison with symptomatic patients. Arch Surg 2003; 138: 427-433; discussion 433-434

5 Klöppel G, Solcia E, Longnecker DS, Capella C, Sobin LH. Histological typing of tumours of the exocrine pancreas. In: World Health Organization International Histological Classification of Tumours. 2nd ed. Berlin: Springer, 1996: 1-61

6 Longnecker DS, Adler G, Hruban RH, Kloppel G. Intraductal papillary-mucinous neoplasms of the pancreas. In: Hamilton SR, Aaltonen LA, editors. World Health Organization Classification of Tumors. Pathology and Genetics of Tumors of the Digestive System. Lyon: IARC Press, 2000: 237-241 
7 Sugiyama M, Atomi Y. Intraductal papillary mucinous tumors of the pancreas: imaging studies and treatment strategies. Ann Surg 1998; 228: 685-691

8 Furukawa T, Takahashi T, Kobari M, Matsuno S. The mucushypersecreting tumor of the pancreas. Development and extension visualized by three-dimensional computerized mapping. Cancer 1992; 70: 1505-1513

9 Procacci C, Carbognin G, Biasiutti C, Guarise A, Ghirardi C, Schenal G. Intraductal papillary mucinous tumors of the pancreas: spectrum of $\mathrm{CT}$ and MR findings with pathologic correlation. Eur Radiol 2001; 11: 1939-1951

10 Irie H, Honda H, Aibe H, Kuroiwa T, Yoshimitsu K, Shinozaki K, Yamaguchi K, Shimada M, Masuda K. MR cholangiopancreatographic differentiation of benign and malignant intraductal mucin-producing tumors of the pancreas. AJR Am J Roentgenol 2000; 174: 1403-1408

11 Yamaguchi K, Chijiwa K, Shimizu S, Yokohata K, Morisaki $\mathrm{T}$, Tanaka M. Comparison of endoscopic retrograde and magnetic resonance cholangiopancreatography in the surgical diagnosis of pancreatic diseases. Am J Surg 1998; 175: 203-208

12 Koito K, Namieno T, Ichimura T, Yama N, Hareyama M, Morita K, Nishi M. Mucin-producing pancreatic tumors: comparison of MR cholangiopancreatography with endoscopic retrograde cholangiopancreatography. Radiology 1998; 208: 231-237

13 Yamao K, Nakamura T, Suzuki T, Sawaki A, Hara K, Kato T, Okubo K, Matsumoto K, Shimizu Y. Endoscopic diagnosis and staging of mucinous cystic neoplasms and intraductal papillary-mucinous tumors. J Hepatobiliary Pancreat Surg 2003; 10: 142-146

14 Vullierme MP, Giraud-Cohen M, Hammel P, Sauvanet A, Couvelard A, O'Toole D, Levy P, Ruszniewski P, Vilgrain $\mathrm{V}$. Malignant intraductal papillary mucinous neoplasm of the pancreas: in situ versus invasive carcinoma surgical resectability. Radiology 2007; 245: 483-490

15 Ogawa H, Itoh S, Ikeda M, Suzuki K, Naganawa S. Intraductal papillary mucinous neoplasm of the pancreas: assessment of the likelihood of invasiveness with multisection CT. Radiology 2008; 248: 876-886

16 Raimondo M, Tachibana I, Urrutia R, Burgart LJ, DiMagno EP. Invasive cancer and survival of intraductal papillary mucinous tumors of the pancreas. Am J Gastroenterol 2002; 97: 2553-2558

17 Kawai M, Uchiyama K, Tani M, Onishi H, Kinoshita H, Ueno M, Hama T, Yamaue H. Clinicopathological features of malignant intraductal papillary mucinous tumors of the pancreas: the differential diagnosis from benign entities. Arch Surg 2004; 139: 188-192

18 Oh HC, Kim MH, Hwang CY, Lee TY, Lee SS, Seo DW, Lee SK. Cystic lesions of the pancreas: challenging issues in clinical practice. Am J Gastroenterol 2008; 103: 229-239; quiz 228, 240

19 Freeman HJ. Intraductal papillary mucinous neoplasms and other pancreatic cystic lesions. World J Gastroenterol 2008; 14: 2977-2979

20 Furuta K, Watanabe H, Ikeda S. Differences between solid and duct-ectatic types of pancreatic ductal carcinomas. Cancer 1992; 69: 1327-1333

21 Tanaka M, Kobayashi K, Mizumoto K, Yamaguchi K. Clinical aspects of intraductal papillary mucinous neoplasm of the pancreas. J Gastroenterol 2005; 40: 669-675

22 Sohn TA, Yeo CJ, Cameron JL, Hruban RH, Fukushima N, Campbell KA, Lillemoe KD. Intraductal papillary mucinous neoplasms of the pancreas: an updated experience. Ann Surg 2004; 239: 788-797; discussion 797-799

23 Lopez Hänninen E, Amthauer H, Hosten N, Ricke J, Böhmig M, Langrehr J, Hintze R, Neuhaus P, Wiedenmann B, Rosewicz S, Felix R. Prospective evaluation of pancreatic tumors: accuracy of MR imaging with MR cholangiopancreatography and MR angiography. Radiology 2002; 224: $34-41$
24 Gigot JF, Deprez P, Sempoux C, Descamps C, Metairie S, Glineur D, Gianello P. Surgical management of intraductal papillary mucinous tumors of the pancreas: the role of routine frozen section of the surgical margin, intraoperative endoscopic staged biopsies of the Wirsung duct, and pancreaticogastric anastomosis. Arch Surg 2001; 136: 1256-1262

25 Terris B, Ponsot P, Paye F, Hammel P, Sauvanet A, Molas G, Bernades P, Belghiti J, Ruszniewski P, Fléjou JF. Intraductal papillary mucinous tumors of the pancreas confined to secondary ducts show less aggressive pathologic features as compared with those involving the main pancreatic duct. Am J Surg Pathol 2000; 24: 1372-1377

26 Doi R, Fujimoto K, Wada M, Imamura M. Surgical management of intraductal papillary mucinous tumor of the pancreas. Surgery 2002; 132: 80-85

27 Gourgiotis S, Ridolfini MP, Germanos S. Intraductal papillary mucinous neoplasms of the pancreas. Eur J Surg Oncol 2007; 33: 678-684

28 Carbognin G, Zamboni G, Pinali L, Chiara ED, Girardi V, Salvia R, Mucelli RP. Branch duct IPMTs: value of crosssectional imaging in the assessment of biological behavior and follow-up. Abdom Imaging 2006; 31: 320-325

29 Matsumoto T, Aramaki M, Yada K, Hirano S, Himeno Y, Shibata K, Kawano K, Kitano S. Optimal management of the branch duct type intraductal papillary mucinous neoplasms of the pancreas. J Clin Gastroenterol 2003; 36: 261-265

30 Kitagawa Y, Unger TA, Taylor S, Kozarek RA, Traverso LW. Mucus is a predictor of better prognosis and survival in patients with intraductal papillary mucinous tumor of the pancreas. J Gastrointest Surg 2003; 7: 12-18; discussion 18-19

31 Sugiyama M, Izumisato $\mathrm{Y}$, Abe N, Masaki T, Mori T, Atomi Y. Predictive factors for malignancy in intraductal papillarymucinous tumours of the pancreas. Br J Surg 2003; 90: 1244-1249

32 Salvia R, Fernández-del Castillo C, Bassi C, Thayer SP, Falconi M, Mantovani W, Pederzoli P, Warshaw AL. Mainduct intraductal papillary mucinous neoplasms of the pancreas: clinical predictors of malignancy and long-term survival following resection. Ann Surg 2004; 239: 678-685; discussion 685-687

33 Kimura W, Sasahira N, Yoshikawa T, Muto T, Makuuchi M. Duct-ectatic type of mucin producing tumor of the pancreas-new concept of pancreatic neoplasia. Hepatogastroenterology 1996; 43: 692-709

34 Takada A, Itoh S, Suzuki K, Iwano S, Satake H, Ota T, Ikeda M, Ishigaki T. Branch duct-type intraductal papillary mucinous tumor: diagnostic value of multiplanar reformatted images in multislice CT. Eur Radiol 2005; 15: 1888-1897

35 Sai JK, Suyama M, Kubokawa Y, Yamanaka K, Tadokoro H, Iida Y, Sato N, Suda K, Nobukawa B, Maehara T. Management of branch duct-type intraductal papillary mucinous tumor of the pancreas based on magnetic resonance imaging. Abdom Imaging 2003; 28: 694-699

36 Choi BS, Kim TK, Kim AY, Kim KW, Park SW, Kim PN, Ha HK, Lee MG, Kim SC. Differential diagnosis of benign and malignant intraductal papillary mucinous tumors of the pancreas: MR cholangiopancreatography and MR angiography. Korean J Radiol 2003; 4: 157-162

37 Sahani DV, Kadavigere R, Blake M, Fernandez-Del Castillo C, Lauwers GY, Hahn PF. Intraductal papillary mucinous neoplasm of pancreas: multi-detector row $\mathrm{CT}$ with $2 \mathrm{D}$ curved reformations--correlation with MRCP. Radiology 2006; 238: 560-569

38 Kawamoto S, Lawler LP, Horton KM, Eng J, Hruban RH, Fishman EK. MDCT of intraductal papillary mucinous neoplasm of the pancreas: evaluation of features predictive of invasive carcinoma. AJR Am I Roentgenol 2006; 186: 687-695 